\title{
The sunburn response in human skin is characterized by sequential eicosanoid profiles that may mediate its early and late phases
}

\author{
Lesley E. Rhodes, ${ }^{*, 1}$ Karl Gledhill, ${ }^{\dagger}$ Mojgan Masoodi, ${ }^{\ddagger}$ Ann K. Haylett, ${ }^{*}$ \\ Margaret Brownrigg,* Anthony J. Thody, ${ }^{*}$ Desmond J. Tobin, ${ }^{\dagger}$ and Anna Nicolaou ${ }^{\dagger,+}$ \\ *Photobiology Unit, Dermatological Sciences, School of Translational Medicine, University of \\ Manchester, Salford Royal National Health Service Foundation Hospital, Manchester Academic \\ Health Sciences Centre, Manchester, UK; ${ }^{\dagger}$ Centre for Skin Sciences, School of Life Sciences, and \\ ${ }^{\ddagger}$ School of Pharmacy, University of Bradford, Bradford, UK; and ${ }^{\$}$ School of Clinical and Laboratory \\ Sciences, University of Newcastle upon Tyne, Newcastle upon Tyne, UK
}

ABSTRACT Sunburn is a commonly occurring acute inflammatory process, with dermal vasodilatation and leukocyte infiltration as central features. Ultraviolet (UV) B-induced hydrolysis of membrane phospholipids releases polyunsaturated fatty acids, and their subsequent metabolism by cyclooxygenases (COXs) and lipoxygenases (LOXs) may produce potent eicosanoid mediators modulating different stages of the inflammation. Our objective was to identify candidate eicosanoids formed during the sumburn reaction in relation to its clinical and histological course. We exposed skin of healthy humans $(n=32)$ to UVB and, for $72 \mathrm{~h}$, examined expression of proinflammatory and antiinflammatory eicosanoids using LC/ESI-MS/MS, and examined immunohistochemical expression of COX-2, 12-LOX, 15-LOX, and leukocyte markers, while quantifying clinical erythema. We show that vasodilatory prostaglandins (PGs) $\mathrm{PGE}_{2}, \mathrm{PGF}_{2 \alpha}$, and $\mathrm{PGE}_{3}$ accompany the erythema in the first $24-48 \mathrm{~h}$, associated with increased COX-2 expression at $24 \mathrm{~h}$. Novel, potent leukocyte chemoattractants 11-, 12-, and 8-monohydroxy-eicosatetraenoic acid (HETE) are elevated from 4 to $72 \mathrm{~h}$, in association with peak dermal neutrophil influx at $24 \mathrm{~h}$, and increased dermal $\mathrm{CD}^{+}$lymphocytes and 12- and 15-LOX expression from 24 to $72 \mathrm{~h}$. Anti-inflammatory metabolite 15-HETE shows later expression, peaking at $72 \mathrm{~h}$. Sunburn is characterized by overlapping sequential profiles of increases in COX products followed by LOX products that may regulate subsequent events and ultimately its resolution.-Rhodes, L. E., Gledhill, K., Masoodi, M., Haylett, A. K., Brownrigg, M., Thody, A. J., Tobin, D. J., Nicolaou, A. The sumburn response in human skin is characterized by sequential eicosanoid profiles that may mediate its early and late phases. FASEB J. 23, 3947-3956 (2009). www.fasebj.org

Key Words: hydroxyeicosatetraenoic acids $\cdot$ prostaglandins - cyclooxygenase $\cdot$ lipoxygenase $\cdot$ leukocytes

Acute ultraviolet (UV) B Exposure of the skin produces sunburn, an inflammatory response evident visually as erythema and characterized histologically by a mixed dermal neutrophilic and lymphocytic infiltrate. Peak vasodilatation is reached at $24 \mathrm{~h} \mathrm{(1)} \mathrm{and}$ neutrophil infiltration at 24-48 h (2-4), while dermal infiltration by $\mathrm{T}$ lymphocytes may exhibit a later time course (5). Whereas prostaglandin (PG) $\mathrm{E}_{2}$ and nitric oxide have roles in the vasodilatation $(1,6,7)$, and cytokines, including interleukin-8, contribute to the leukocyte infiltration (3), the mediation of induction and resolution of the sunburn response is incompletely understood and is anticipated to involve a wider range of eicosanoids.

Skin displays highly active metabolism of polyunsaturated fatty acids (PUFAs), resulting in the production of eicosanoids that modulate physiological processes at low concentrations and elicit inflammatory reactions at higher levels (8). Activation of membrane phospholipase $\mathrm{A}_{2}$ by UVB effects release of fatty acids, notably the $\omega(n)-6$ PUFA arachidonic acid (AA; 20:4n-6), and potentially the n-3 PUFA eicosapentaenoic acid (EPA; 20:5n-3), which has also been detected in human skin (9) (Scheme 1). Subsequently, these PUFAs may be metabolized by cyclooxygenases (COXs) and lipoxygenases (LOXs) to a wide range of eicosanoids and other lipid mediators. High COX-2, 12-LOX, and 15-LOX activity is reported in epidermal cells, and infiltrating neutrophils may possess 5-LOX activity $(8,10)$. Considerable species differences are reported for LOX expression (11), and additional fatty acid metabolism by cytochrome P-450 and nonenzymatic oxidation may

\footnotetext{
${ }^{1}$ Correspondence: Photobiology Unit, Dermatological Sciences, University of Manchester, Salford Royal NHS Foundation Hospital, Manchester, M6 8HD, UK. E-mail: lesley.e. rhodes@manchester.ac.uk

This is an Open Access article distributed under the terms of the Creative Commons Attribution Non-Commercial License (http://creativecommons.org/licenses/by-nc/3.0/us/) which permits unrestricted non-commercial use, distribution, and reproduction in any medium, provided the original work is properly cited.

doi: $10.1096 /$ fj.09-136077
} 
contribute to production of a wide diversity of metabolites (12).

Following UVB exposure, COX-2 expression was found to be elevated in human skin when assessed at the single time point of $24 \mathrm{~h}$ (13). Recently, UVB was reported to modulate 12-LOX and 15-LOX expression in a keratinocyte cell line, with reciprocal regulation of these LOXs, suppressing 12-LOX, while up-regulating 15-LOX (14). However, there is scant information concerning the effects of UVB on LOX expression in human skin. Furthermore, through technical limitations, only a restricted range of UV-induced skin eicosanoids have been examined to date; consequently, detailed characterization of eicosanoids possessing properties that potentially mediate the course of human sunburn is lacking. Recently developed lipidomic assays based on electrospray ionization-liquid chromatography-tandem mass spectrometry (ESI-LC-MS-MS) now permit assessment of a wide range of metabolites $(15,16)$.

We examined the expression and temporal relationship of candidate eicosanoids that may mediate both the early and later phases of vasodilatation and leukocyte infiltration, and potentially also the resolution phase, of the sunburn response, in 32 healthy humans. The clinical (skin erythema) and histological (leukocyte infiltration) response was followed for $72 \mathrm{~h}$, with detailed characterization of cutaneous eicosanoid expression, and direct assessment of UVB regulation of COX-2, 12-LOX, and 15-LOX expression over this period. We specifically examined for vasodilatory prostanoids derived through COX metabolism of both $\omega-6$ and $\omega-3$ PUFAs (i.e., AA and EPA), and for a range of hydroxyeicosatetraenoic acids (HETEs) expressing chemoattractant properties for neutrophils and lymphocytes $(17,18)$ or anti-inflammatory properties $(11)$.

\section{MATERIALS AND METHODS}

\section{Subjects}

The study group comprised 32 healthy white Caucasian subjects of mean age $40 \mathrm{yr}$ (range 19 to $58 \mathrm{yr}$; 20 female) and sun-reactive skin types I-IV. Exclusions from the study were sunbathing or sunbed use in the prior 3 mo, photosensitizing or anti-inflammatory medication, and history of skin cancer or photosensitivity disorders. The study conformed to the Declaration of Helsinki 2000, North Manchester Research Ethics Committee approval was obtained, and all volunteers gave written informed consent.

\section{UV irradiation}

The UV radiation (UVR) source used was a fluorescent UVB lamp, (Waldmann UV6; emission 290-400 nm, peak $313 \mathrm{~nm}$; Herbert Waldmann GmbH, Villingen-Schwenningen, Germany). Minimal erythema dose (MED) testing was performed by applying a geometric series of UV doses ranging from 13 to $128 \mathrm{~mJ} / \mathrm{cm}^{2}$ of erythemally weighted UVR in a horizontal row to the upper buttock skin. The MED was assessed at $24 \mathrm{~h}$, and defined as the lowest dose of UVB that resulted in detectable erythema. Volunteers were given MED-related doses in order to standardize the UVB challenge according to individual erythemal sensitivity. Three sites on the buttock skin were irradiated with 4 times the individual's MED of UVB, a dose sufficient to produce a well-defined clinical and histological inflammatory response. These sites were utilized for erythema time course determination and suction blister fluid sampling ( $n=22$ subjects) or skin-punch biopsy sampling for immunohistochemical investigations $(n=10$ subjects $)$.

\section{Assessment of erythemal responses}

Erythemal responses were quantified using a reflectance instrument (Diastron, Andover, UK), which gives an erythema index related to the blood content of the superficial dermis. Triplicate measurements were taken from the test sites and adjacent unirradiated skin, and the means were calculated.

\section{Suction blister sampling}

Suction blister fluid was sampled from unirradiated skin and from skin at 4, 18, 24, 48, and $72 \mathrm{~h}$ following a dose of UVB $(4 \times$ MED $)$. Each volunteer provided a sample from an unirradiated site on one buttock, and samples from 3 irradiated sites on the contralateral buttock, each site being sampled on one occasion. Half of the volunteers were sampled at baseline, 4, 18, and $24 \mathrm{~h}$, and the others at baseline, 24, 48, and $72 \mathrm{~h}$, with erythema readings taken at the same time points. Suction blister cups with 1-cm central aperture were applied with a vacuum pressure of $250 \mathrm{~mm} \mathrm{Hg}$, as described previously (19). When blisters had formed (after $\sim 90 \mathrm{~min}$ ), the fluid was aspirated with a 23-gauge needle, snap-frozen, and stored at $-80^{\circ} \mathrm{C}$ until analysis.

\section{Lipidomic analysis}

Lipidomic analyses were performed as described by Masoodi et al. $(15,16)$. Briefly, blister fluid samples (typical volumes $50-200 \mu \mathrm{l})$ were diluted with methanol-water $(15 \% \mathrm{wt} / \mathrm{wt})$ to a final volume of $3 \mathrm{ml}$. Internal standards (40 ng PGB2- $d 4$ and 80 ng 12-HETE- $d 8$; Cayman Chemicals, Ann Arbor, MI, USA) were added to each sample. The resultant solutions were acidified to $\mathrm{pH} 3$ and immediately applied to preconditioned solid-phase extraction cartridges (C18-E; Phenomenex, Macclesfield, UK) to extract the lipid mediators. Chromatographic analysis was performed on a C18 column (Luna 5 $\mu \mathrm{m}$; Phenomenex) using a Waters Alliance 2695 HPLC pump coupled to an ESI triple-quadrupole Quattro Ultima mass spectrometer (Waters, Elstree, UK). Instrument control and data acquisition were performed using MassLynx 4.0 software (Waters). The following multiple reaction monitoring (MRM) transitions were used for the assay of prostanoids and hydroxy fatty acids: $\mathrm{PGE}_{2}, \mathrm{~m} / z 351>271$; 13,14-dihydro-15-keto $\mathrm{PGE}_{2}$, $m / z 351>333,349>113 ; \mathrm{PGF}_{2 \alpha}, m / z 353>193 ; 13,14$-dihydro15-keto $\mathrm{PGF}_{2 \alpha}, \mathrm{m} / z 353>113 ; \mathrm{PGE}_{1}, \mathrm{~m} / z 353>317$; 13,14dihydro-15-keto-PGE $1, m / z 353>335 ; \mathrm{PGE}_{3}, \mathrm{~m} / z 349>269$; LTB $_{4}, m / z 335>195$; 11 -HETE, $m / z 319>167$; 12 -HETE, $m / z$ $319>179$; 8-HETE, $m / z 319>155$; and 15-HETE, $m / z 319>$ 175. Results are expressed as picograms of metabolite per milligram of protein, based on calibration lines constructed with commercially available eicosanoid standards (Cayman Chemicals). Protein content was estimated using the Bio-Rad protein assay kit with BSA as standard (Bio-Rad, Hemel Hempstead, UK).

\section{Immunohistochemical assessment}

Skin-punch biopsies (5-mm diameter) were sampled from unirradiated skin and from skin at 4, 24, and $72 \mathrm{~h}$ following 
exposure to $4 \times$ MED of UVB (see above). Biopsies were snap-frozen and stored at $-80^{\circ} \mathrm{C}$ prior to immunohistochemical analysis. Frozen sections $(6 \mu \mathrm{m})$ were air-dried before fixation in ice-cold acetone (Fisher Scientific UK, Loughborough, UK) for $10 \mathrm{~min}$. Endogenous peroxidase was quenched in hydrated tissue sections with $0.5 \% \quad \mathrm{H}_{2} \mathrm{O}_{2}$ (Sigma-Aldrich Co., Gillingham, UK) before blocking with $10 \%$ goat serum (Sigma-Aldrich) for $1 \mathrm{~h}$. Primary antibody was added to the sections at the required dilution and incubated overnight at $4^{\circ} \mathrm{C}$. The primary antibodies used in this study were as follows. Neutrophil elastase: MAB 1056, dilution 1:70 (Chemicon Europe, Chandlers Ford, UK); $\mathrm{CD}^{+}{ }^{+}$NCL-CD3, dilution 1:40 (NovoCastra Reagents, Leica Biosystems, Newcastle on Tyne, UK); 12-LOX: ab23678, dilution 1:200 (Abcam plc, Cambridge, UK); 15-LOX: 10004454, dilution 1:100 (Cayman Chemical, Boldon, UK); COX-2: ALX-210-712-1, dilution 1:100 (Alexis Biochemicals, Lausen, Switzerland). After washing in PBS, skin sections were incubated with biotinylated anti-mouse secondary antibody (DakoCytomation, Ely, UK) for $30 \mathrm{~min}$, washed in PBS, and incubated with streptavidin peroxidase (DakoCytomation) for $30 \mathrm{~min}$. Sections were developed using aminoethylcarbazole chromogen (Vector Laboratories, Peterborough, UK) for 5-10 min, washed in distilled water, lightly counterstained in Meyers hematoxylin (Sigma-Aldrich), and mounted in glycergel mounting medium (DakoCytomation). The sections were assessed using a Nikon Eclipse $80 \mathrm{i}$ microscope at $\times 200$ view and a Nikon Digital Sight DS-U1 camera (Nikon UK, Kingston on Thames, UK).

\section{Quantification of immunohistochemical staining}

Slides were masked prior to assessment. Neutrophils and $\mathrm{CD}^{+}$cells were counted in 3 randomly selected epidermal and dermal high-power fields $(\mathrm{hpf})$ at $\times 400$. This technique was employed for each individual at each of 4 time points. COX and LOX staining was quantified in terms of relative staining intensity, according to the following scoring system: $0=$ no staining, $1=$ weak staining, $2=$ moderate staining, $3=$ intense staining. 12-LOX, 15-LOX, and COX-2 were graded in epidermal and dermal hpf at $\times 200$. Assessment was made for each individual at each of the 4 time points.

\section{Statistical analysis}

Data were analyzed with StatsDirect (Stats Direct, Altrincham, UK). Nonparametric data were analyzed using the KruskalWallis test with adjustment for multiple comparisons, and parametric data were analyzed using 1-way ANOVA with Bonferroni correction. All results are compared with levels in non-UV-exposed tissue unless otherwise stated. Statistical significance was accepted at the $P<0.05$ level.

\section{RESULTS}

\section{UVB-erythema time course}

Erythema was clinically visible at $4 \mathrm{~h}$ following UVB exposure, with a significant elevation of the erythema index at this time point, rising from a mean $\pm \mathrm{SE}$ baseline value of $39.9 \pm 3.6$ to $97.2 \pm 13.4$ at $4 \mathrm{~h}$ $(P<0.001)$. The erythema index peaked at $18-24 \mathrm{~h}$ after UVB exposure (160.8 \pm 6.3 and $171.1 \pm 3.6$, respectively) and remained elevated at $72 \mathrm{~h}$ (156.6 \pm 6.4 , $P<0.001)$ (Fig. 1).

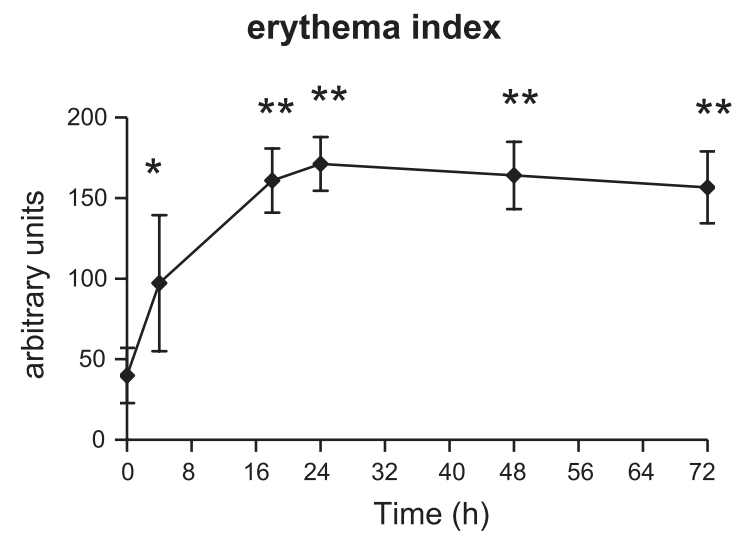

Figure 1. Time course of sunburn erythema in human skin. Buttock skin of healthy human volunteers $(n=22)$ was exposed to a UVB dose equivalent to $4 \times$ each volunteer's sunburn threshold $(4 \times$ MED). Erythemal response was quantified using a reflectance technique, giving an erythema index (EI) proportional to the blood content of the superficial dermis. Results are expressed as mean \pm SE EI in unexposed skin and in skin at $4,18,24,48$, and $72 \mathrm{~h}$ after UVB exposure. $* P<0.05, * * P<0.001$ vs. unexposed skin.

\section{Effect of UVB on COX-mediated eicosanoid production}

$\mathrm{PGE}_{2}$ and metabolite

Analysis of suction blister fluid from unexposed skin revealed baseline levels of $\mathrm{PGE}_{2}$ and its inactive metabolite 13,14-dihydro-15-keto $\mathrm{PGE}_{2}$ of $26.83 \pm 3.1$ and $31.7 \pm 2.63 \mathrm{pg} / \mathrm{mg}$ protein, respectively. Following $\mathrm{UVB}, \mathrm{PGE}_{2}$ levels were above the baseline level at all time points $4-72 \mathrm{~h}$, with statistically significant eleva-

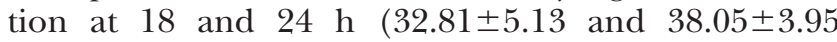
$\mathrm{pg} / \mathrm{mg}$ protein, respectively; $P=0.02$ ) (Fig. 2A), while 13,14-dihydro-5-keto $\mathrm{PGE}_{2}$ was significantly elevated at $72 \mathrm{~h}(50.45 \pm 6.86 \mathrm{pg} / \mathrm{mg}$ protein; $P=0.02)$ (Fig. $2 B$ ).

$P G F_{2 \alpha}$ and metabolite

Baseline levels of PGF $_{2 \alpha}$ and 13,14-dihydro-15-keto $\mathrm{PGF}_{2 \alpha}$ were $30.47 \pm 3.53$ and $0.81 \pm 0.81 \mathrm{pg} / \mathrm{mg}$ protein, respectively. Prostaglandin $\mathrm{F}_{2 \alpha}$ also showed a significant rise at $18 \mathrm{~h}(44.84 \pm 6.66 \mathrm{pg} / \mathrm{mg}$ protein; $P=0.03$ ), but in contrast to $\mathrm{PGE}_{2}$, it returned to baseline levels by $24 \mathrm{~h}(30.1 \pm 2.57 \mathrm{pg} / \mathrm{mg}$ protein) (Fig. 2C). However, the inactive $\mathrm{PGF}_{2 \alpha}$ metabolite 13,14-dihydro-15-keto $\mathrm{PGF}_{2}$, was significantly elevated at 48 and $72 \mathrm{~h}(17.62 \pm 4.39 \mathrm{pg} / \mathrm{mg}$ protein, $P=0.003$ and $13.65 \pm 5.02 \mathrm{pg} / \mathrm{mg}$ protein, $P=0.049$, respectively) (Fig. $2 D$ ).

\section{$P G E_{1}$ and metabolite}

Baseline levels of $\mathrm{PGE}_{1}$ and 13,14-dihydro-15-keto $\mathrm{PGE}_{1}$ were $17.14 \pm 3.58$ and $7.60 \pm 2.18 \mathrm{pg} / \mathrm{mg}$ protein, respectively. Following UVB, the same overall trend was noted as for the above prostanoids. Although $\mathrm{PGE}_{1}$ 
A

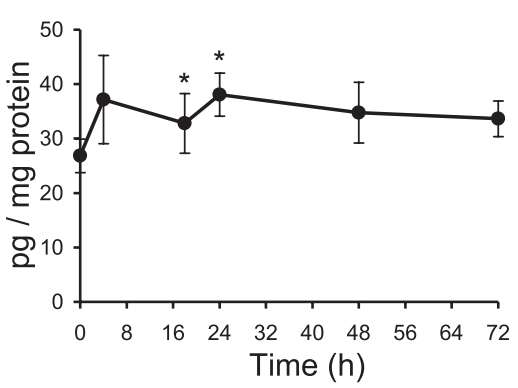

D 13,14 dihydro-15-keto $\mathrm{PGF}_{2 \alpha}$
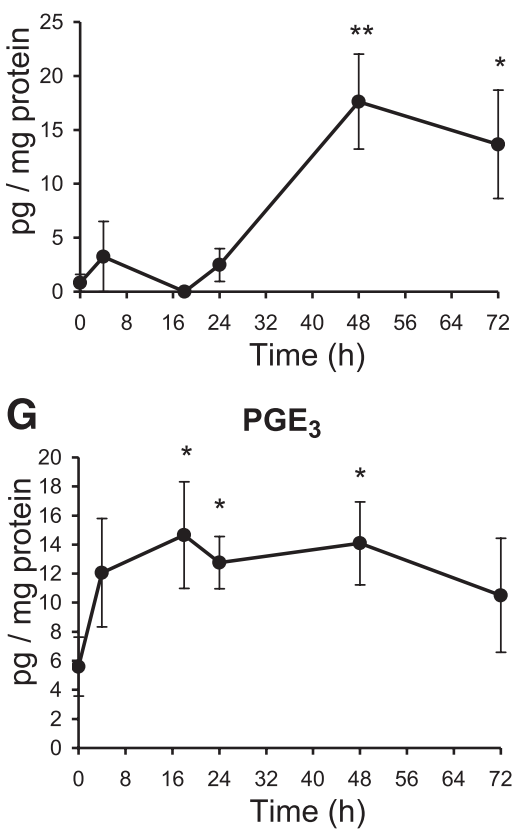

B 13,14 dihydro-15-keto $\mathrm{PGE}_{2}$

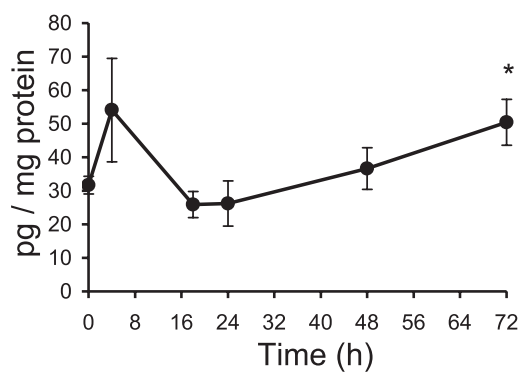

E

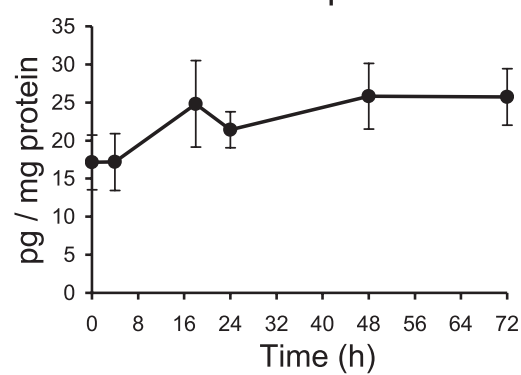

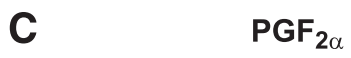

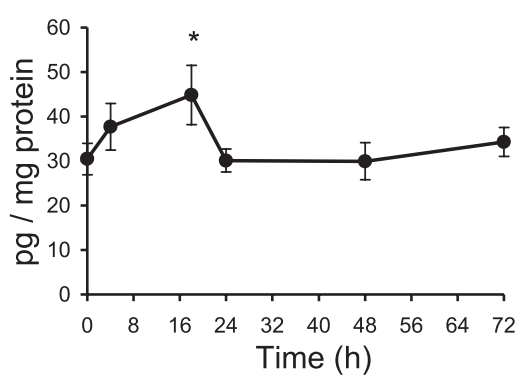

F 13,14 dihydro-15-keto $\mathrm{PGE}_{1}$

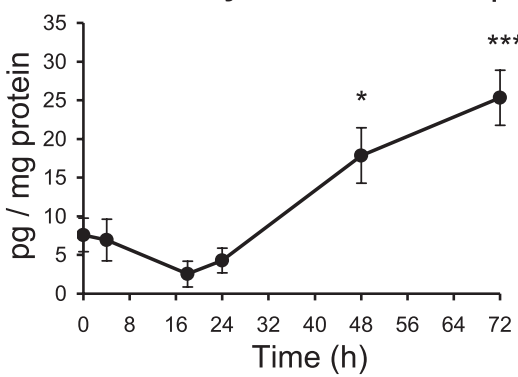

Figure 2. Levels of $\omega-6$ and $\omega-3$ PUFA-derived prostanoids and their metabolites in cutaneous blister fluid during sunburn response. Panels show $\mathrm{PGE}_{2}$ (A), 13,14-dihydro-15-keto $\mathrm{PGE}_{2}(B), \mathrm{PGF}_{2 \alpha}(C)$, 13,14-dihydro-15-keto $\mathrm{PGF}_{2 \alpha}$ $(D), \mathrm{PGE}_{1}(E), 13,14$-dihydro-15-keto $\mathrm{PGE}_{1}(F)$, and $\mathrm{PGE}_{3}(G)$. Buttock skin of healthy volunteers $(n=22)$ was exposed to $4 \times$ MED of UVB. Blisters were formed on UVB-exposed and unexposed skin, using suction cups and a vacuum pressure of $250 \mathrm{mmHg}$. Blister fluid samples were semipurified by solid phase extraction, followed by analysis by ESI/LC-MS/MS. Eicosanoids were identified by their $\mathrm{m} / \mathrm{z}$ value and mass spectra, and quantitation was performed using multiple reaction monitoring-based assays. Results are expressed as mean $\pm \mathrm{SE}$ mediator $(\mathrm{pg} / \mathrm{mg}$ protein) in unexposed skin and at $4,18,24,48$, and $72 \mathrm{~h}$ after UVB exposure. $* P<0.05, * * P<0.01, * * * P<$ 0.001 vs. unexposed levels.

concentration was not significantly elevated over baseline levels (Fig. 2E), its inactive metabolite 13,14-dihydro-15 keto-PGE 1 was significantly elevated at 48 and $72 \mathrm{~h}$ postexposure $(17.86 \pm 3.58 \mathrm{pg} / \mathrm{mg}$ protein, $P=$ 0.02 , and $25.33 \pm 3.55 \mathrm{pg} / \mathrm{mg}$ protein, $P=0.0001$, respectively) (Fig. 2F).

$P G E_{3}$

Baseline level of this $\omega$-3-PUFA-derived prostanoid was $5.60 \pm 2.03 \mathrm{pg} / \mathrm{mg}$ protein. Following UVB, $\mathrm{PGE}_{3}$ increased by $4 \mathrm{~h}(12.06 \pm 3.73 \mathrm{pg} / \mathrm{mg}$ protein $)$ and still appeared elevated above baseline at $72 \mathrm{~h}(10.5 \pm 3.93$ $\mathrm{pg} / \mathrm{mg}$ protein), with significant elevations found at 18 , 24, and $48 \mathrm{~h}(16.65 \pm 3.66 \mathrm{pg} / \mathrm{mg}$ protein, $P=0.04$; $12.76 \pm 1.81 \mathrm{pg} / \mathrm{mg}$ protein, $P=0.04$; and $14.08 \pm 2.85$ $\mathrm{pg} / \mathrm{mg}$ protein, $P=0.03$, respectively) (Fig. $2 G$ ).

\section{Effect of UVB on LOX-mediated eicosanoid production}

8-HETE

Baseline level was $0.64 \pm 0.64 \mathrm{pg} / \mathrm{mg}$ protein; following UVB, 8-HETE became significantly elevated at $24 \mathrm{~h}$
(13.78 $\pm 3.69 \mathrm{pg} / \mathrm{mg}$ protein, $P=0.003)$ and showed a progressive rise to $72 \mathrm{~h}(31 \pm 6.11 \mathrm{pg} / \mathrm{mg}$ protein, $P<0.0001)$ (Fig. 3A).

\section{1-HETE}

Baseline level was $1.17 \pm 0.7 \mathrm{pg} / \mathrm{mg}$ protein; 11-HETE was significantly elevated at the first time point of assessment following UVB, i.e., $4 \mathrm{~h}$ (5.54 $1.94 \mathrm{pg} / \mathrm{mg}$ protein, $P=0.02)$, peaked at $18 \mathrm{~h}(10.68 \pm 2.45 \mathrm{pg} / \mathrm{mg}$ protein, $P<0.0001)$, and remained elevated to $72 \mathrm{~h}$ (10.54 $3.78 \mathrm{pg} / \mathrm{mg}$ protein, $P=0.0004$ ) (Fig. $3 B$ ).

\section{2-HETE}

Baseline level was $20.25 \pm 9.82 \mathrm{pg} / \mathrm{mg}$ protein. Following UVB, 12-HETE became significantly elevated at $18 \mathrm{~h}(105.85 \pm 34.64 \mathrm{pg} / \mathrm{mg}$ protein, $P=0.007)$, with a progressive rise at subsequent time points and peak level at $72 \mathrm{~h}(251.51 \pm 60.85 \mathrm{pg} / \mathrm{mg}$ protein, $P<0.0001)$ (Fig. 3C).

\section{5-HETE}

Baseline value of 15-HETE was $2.16 \pm 1.37 \mathrm{pg} / \mathrm{mg}$ protein. Following UVB, 15-HETE showed significant 

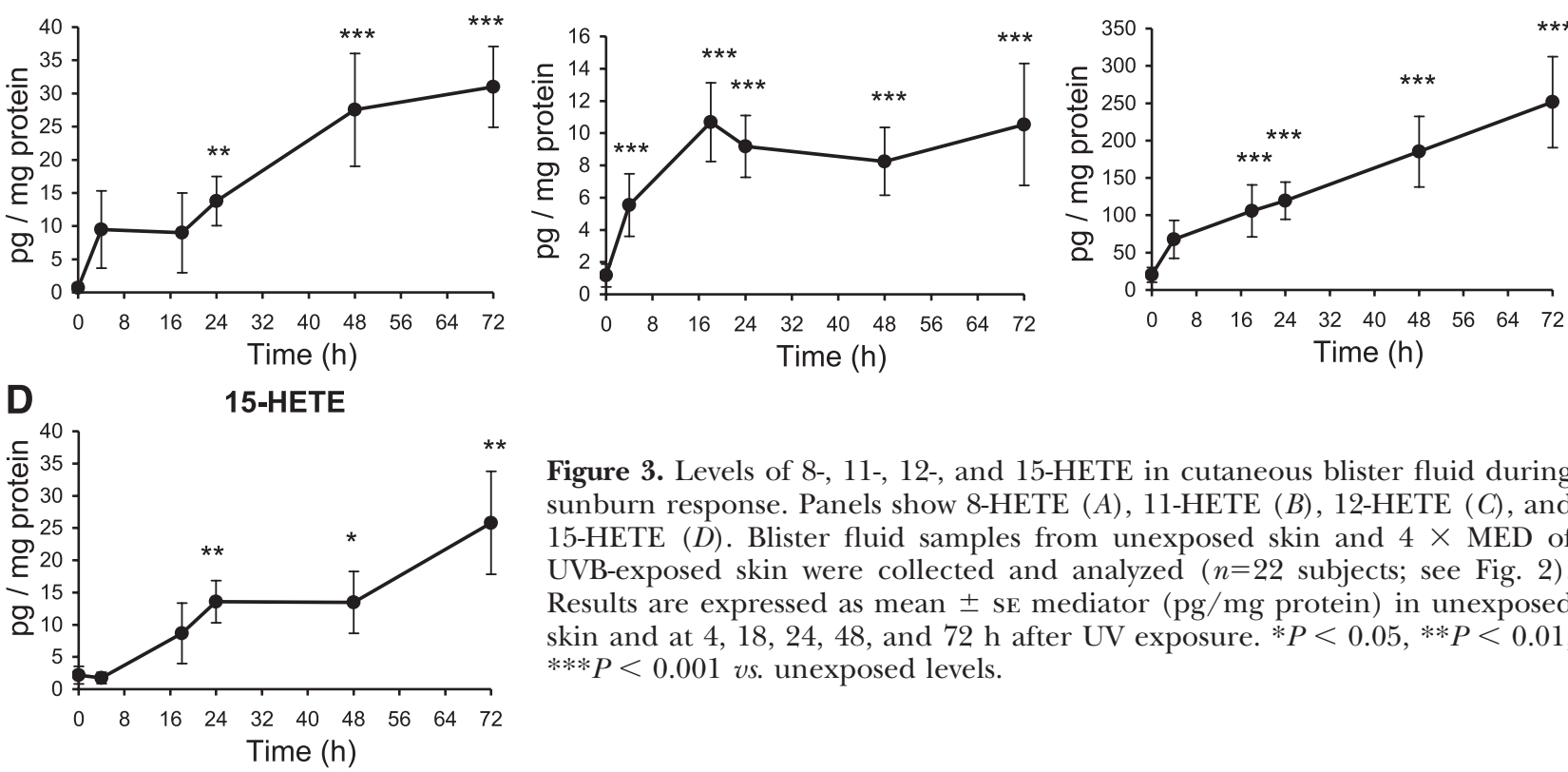

Figure 3. Levels of 8-, 11-, 12-, and 15-HETE in cutaneous blister fluid during sunburn response. Panels show 8-HETE $(A)$, 11-HETE $(B)$, 12-HETE $(C)$, and 15-HETE $(D)$. Blister fluid samples from unexposed skin and $4 \times$ MED of UVB-exposed skin were collected and analyzed ( $n=22$ subjects; see Fig. 2$)$. Results are expressed as mean \pm SE mediator $(\mathrm{pg} / \mathrm{mg}$ protein) in unexposed skin and at $4,18,24,48$, and $72 \mathrm{~h}$ after UV exposure. $* P<0.05$, $* * P<0.01$, $* * * P<0.001$ vs. unexposed levels.

elevation by $24 \mathrm{~h} \quad(13.58 \pm 3.26 \mathrm{pg} / \mathrm{mg}$ protein, $P=0.007)$, and was still rising at the last $(72 \mathrm{~h})$ time point (25.8 $\pm 8 \mathrm{pg} / \mathrm{mg}$ protein, $P=0.002$ ) (Fig. 3D).

$\mathrm{LTB}_{4}$

$\mathrm{LTB}_{4}$ was undetectable at baseline and at all time points following UVB.

\section{Cutaneous leukocytic infiltration following UVB}

\section{Neutrophils}

Neutrophil polymorphs, identified by their staining with antineutrophil elastase antibody, were present in unirradiated epidermal and dermal samples (0.97 \pm 0.65 and $3.07 \pm 1.45$ cells $/ \mathrm{hpf}$, respectively) (Fig. 4). Dermal neutrophil levels peaked at $24 \mathrm{~h}$ after UV exposure (mean $8.6 / \mathrm{hpf} ; P=0.03$ ) returning to baseline levels by $72 \mathrm{~h}$. The number of epidermal neutrophils was not significantly different from baseline levels.

$$
\mathrm{CD}^{+} \text {cells }
$$

Baseline levels of $\mathrm{CD}^{+}$lymphocytes were $0.53 \pm 0.3$ and $10.8 \pm 1.66$ cells $/ \mathrm{hpf}$ in epidermis and dermis, respectively (Fig. 5). The number of $\mathrm{CD}^{+}$-positive cells was significantly elevated above baseline at $24 \mathrm{~h}$ after UVB exposure (mean 22.63 \pm 5.11 cells per hpf; $P=$ $0.02)$, and remained significantly elevated at $72 \mathrm{~h}$ after UVB (mean $24.7 \pm 2.97$ cells/hpf; $P<0.001$ vs. baseline). No significant changes were seen in epidermal levels of $\mathrm{CD}^{+}$cells.

\section{Cutaneous expression of COX-2, 12-LOX, and 15- LOX following UVB}

\section{COX-2}

Baseline staining intensity of COX-2 was $0.14 \pm 0.14$ and $0.71 \pm 0.29$ in the epidermis and dermis, respectively (Fig. 6). A significant increase in COX-2 staining intensity was observed at $24 \mathrm{~h}$ after UVB exposure, for both dermis and epidermis $(1.43 \pm 0.37$ and $1.29 \pm 0.36$; $P=0.04$ and $P=0.03$, respectively).

\section{2-LOX}

Relative baseline staining intensity of 12-LOX was $0.14 \pm 0.14$ and $1.43 \pm 0.3$ for the epidermis and dermis, respectively (Fig. 7). This was significantly elevated in the dermis at $4 \mathrm{~h}$ after UVB exposure (mean $2.29 \pm 0.29 ; P=0.02)$, and in the epidermis at 24 and $72 \mathrm{~h}$ after UVB (mean $1 \pm 0.22$ and $1.29 \pm 0.36 ; P=0.02$ and $P=0.005$, respectively).

\section{$15-L O X$}

Relative baseline staining intensity for 15 -LOX was $0.75 \pm 0.25$ and $1.13 \pm 0.23$ in the epidermis and dermis, respectively (Fig. 8). In the dermis a significant increase relative to baseline was seen at $24 \mathrm{~h}$ after UVB exposure $(2.75 \pm 0.16 P=0.001)$. The epidermis also showed a significant increase in staining intensity at $24 \mathrm{~h}$ after UVB $(2 \pm 0.33 ; P=0.01)$, and this remained significantly elevated at $72 \mathrm{~h}$ after UVB $(1.63 \pm 0.18$; $P=0.02)$.

\section{DISCUSSION}

This study provides for the first time a detailed characterization of the candidate eicosanoid mediators of the 
A

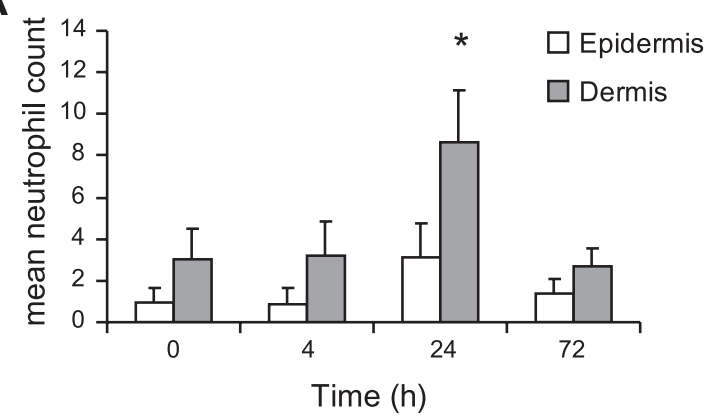

B

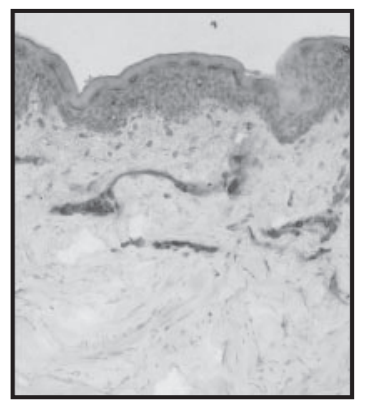

D

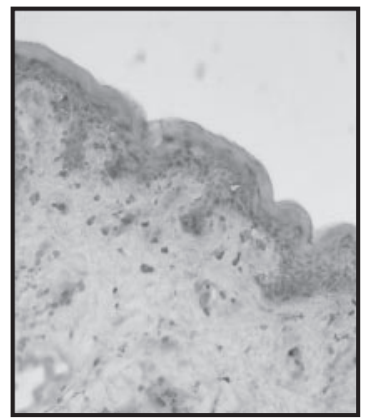

C

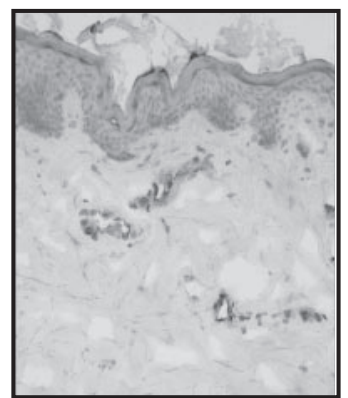

E

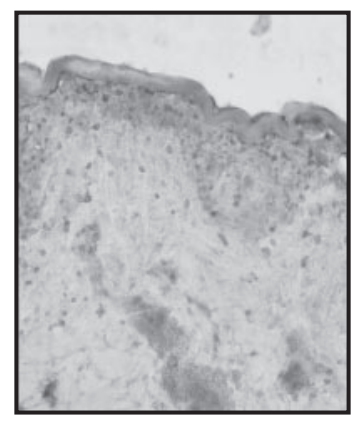

Figure 4. Neutrophil infiltrate in epidermis and dermis during sunburn response. Graphical presentation of time course $(A)$, with representative photomicrographs of sections from unirradiated skin $(B)$ and skin at $4 \mathrm{~h}(C), 24 \mathrm{~h}(D)$, and $72 \mathrm{~h}(E)$ after UVB exposure. Punch biopsy samples were collected from the buttock skin of healthy volunteers prior to and at intervals after exposure to $4 \times$ MED of UVB. Frozen skin sections were immunohistochemically stained using antineutrophil elastase monoclonal antibody. Numbers of cells staining positive per hpf ( $\times 400$ original view) were counted, using 3 fields in random epidermal/dermal interface locations for each time point. Results are expressed as mean $\pm \mathrm{SE}$ cell count; $n=10$. $* P<0.05$ vs. baseline.

sunburn response up to $72 \mathrm{~h}$, identifying bioactive lipid mediators that may be responsible for the principal clinical and histological components of vasodilatation and leukocyte infiltration (Scheme 1). Our data support that a range of prostanoids, including n-3 PUFAderived $\mathrm{PGE}_{3}$, in addition to $\mathrm{n}-6$ PUFA-derived $\mathrm{PGE}_{2}$, are produced during the sunburn reaction. They further suggest that the potent chemoattractants 8-HETE, 11-HETE, and 12-HETE may contribute to the leukocyte influx, while the anti-inflammatory metabolite 15-HETE may serve to limit or aid resolution of the inflammation. Eicosanoid-producing enzymes 12-LOX

and 15-LOX are both up-regulated, in contrast to recent findings in a keratinocyte cell line (14). Expression of COX and LOX does not necessarily reflect enzyme activity. However, we observe that while COX-2 shows significantly increased expression only at $24 \mathrm{~h}$, 12- and 15-LOX show sustained increase in expression at $72 \mathrm{~h}$, consistent with the earlier and later peaks of their respective prostanoid and HETE metabolites during the sunburn response (Scheme 2).

Our results indicate that after an early increase in n-6 PUFA-derived prostaglandins $\mathrm{PGE}_{2}, \mathrm{PGF}_{2 \alpha}$, and $\mathrm{PGE}_{1}$ following UVB exposure, these potent mediators are enzymatically inactivated (Fig. 2), as reflected by increases in their respective 13,14-dihydro-15-keto derivatives. Although it is established that $\mathrm{PGE}_{2}$ contributes

A

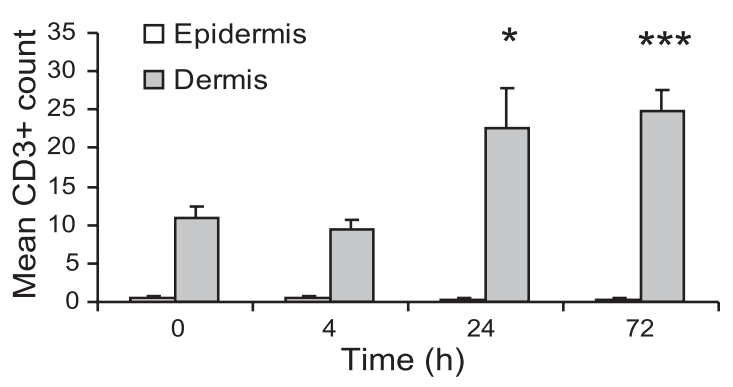

B

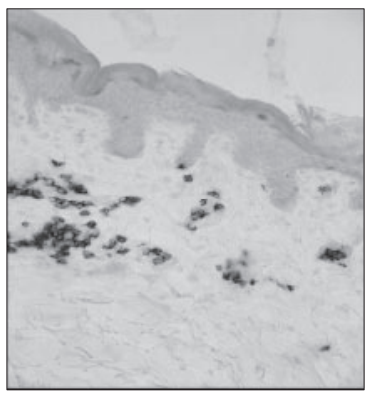

C

D
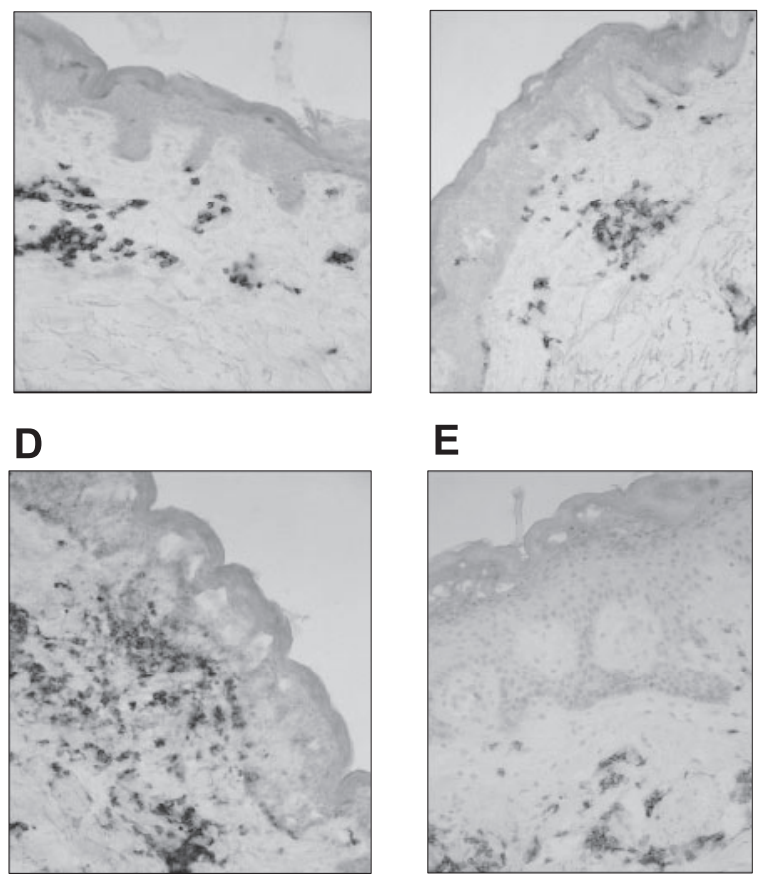

E

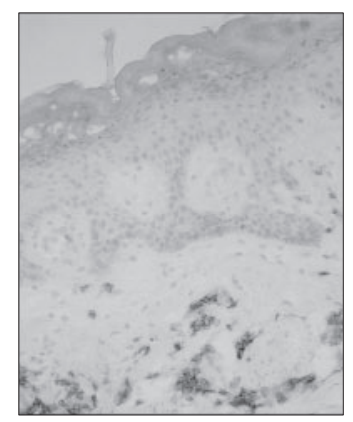

Figure 5. $\mathrm{CD}^{+}$lymphocytic infiltrate in epidermis and dermis during the sunburn response. Graphical presentation of time course $(A)$, with representative photomicrographs of sections from unexposed skin $(B)$ and skin at $4 \mathrm{~h}(C), 24 \mathrm{~h}$ $(D)$, and $72 \mathrm{~h}(E)$ after UVB exposure. Punch biopsy samples were collected from buttock skin of healthy volunteers, and immunohistochemical analysis was performed to determine numbers of $\mathrm{CD}^{+}$cells per hpf (see Fig. 4). Results are expressed as mean \pm sE cell count; $n=10 . * P<0.05, * * * P<$ 0.001 vs. baseline. 
A

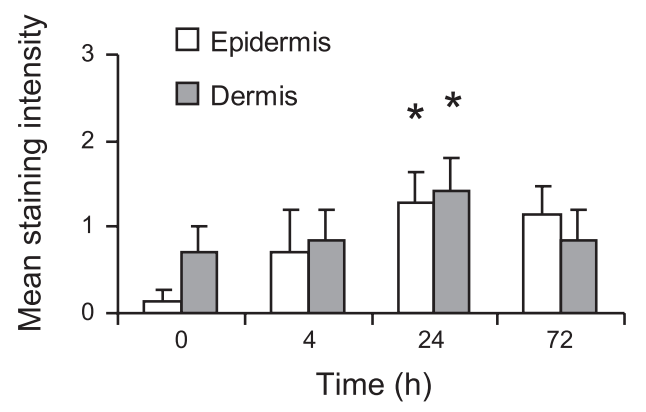

B

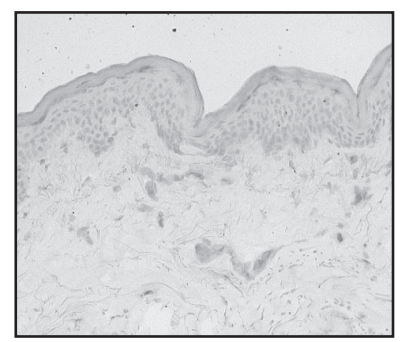

D

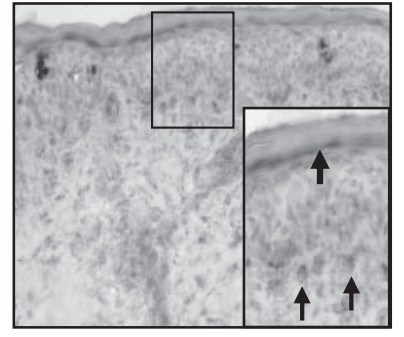

C

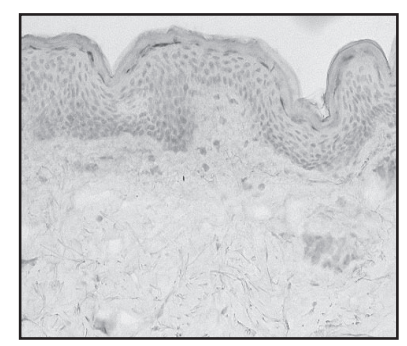

E

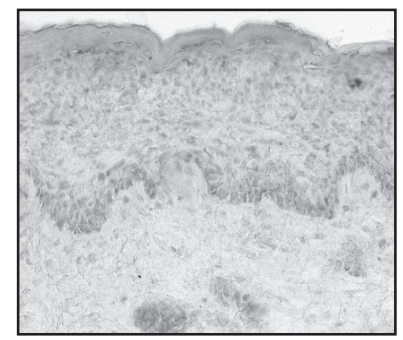

Figure 6. Expression of COX-2 in the epidermis and dermis during sunburn response. Graphical presentation of time course $(A)$, with representative photomicrographs of sections from unexposed skin $(B)$ and skin at $4 \mathrm{~h}(C), 24 \mathrm{~h}(D)$, and $72 \mathrm{~h}(E)$ after UVB exposure. Biopsy samples were collected from buttock skin of healthy individuals, and immunohistochemical analysis was performed to determine levels of COX-2 expression in dermis and epidermis. Frozen sections were scored for relative staining intensity: $0=$ no staining; $1=$ weak staining; $2=$ moderate staining; $3=$ intense staining. Three hpf in random epidermal/dermal interface locations were examined for each time point. Arrows indicate COX-2 staining. Results are expressed as mean \pm SE staining intensity; $n=8$. $* P<0.05$ vs. baseline.

to UVB-induced vasodilatation in the first $24-48 \mathrm{~h}(1$, $6,20)$, the contribution of $\mathrm{PGF}_{2 \alpha}$ to erythema production is uncertain. Intradermal injection of $\mathrm{PGF}_{2 \alpha}$, as with $\mathrm{PGE}_{1}$ and $\mathrm{PGE}_{2}$, can produce skin erythema (21, $22)$, but the relevance of these findings is unclear in view of the higher than physiological doses used; moreover, $\mathrm{PGF}_{2 \alpha}$ is described as a vasoconstrictor in some systems (23). Whereas we did not directly detect a significant increase in the COX-metabolized vasodilator $\mathrm{PGE}_{1}$, derived from dihommogammalinolenic acid, its inactive metabolite was significantly elevated at 48-72 $\mathrm{h}$ after UVB exposure, indicating the earlier elevation of the mediator. This pattern of controlled prostaglandin production suggests an active response

of the tissue to UVR-induced injury. Moreover, $\mathrm{PGE}_{2}$ has complex roles, contributing to tissue repair in addition to mediating vasodilatation and inflammation (24), and inducing COX-2, and thereby its own synthesis (25), while displaying anti-inflammatory effects, including inhibition of 5-LOX (26) and induction of 15-LOX (27-29). Thus, sunburn is a self-resolving model of injury exhibiting preparation for its resolution through the quick deactivation of proinflammatory signals and activation of repair mechanisms.

Interestingly, we found significant elevation of the n-3 PUFA-derived $\mathrm{PGE}_{3}$, from 18 to $48 \mathrm{~h}$ following UV. This mediator has not previously been reported in human skin, although its discovery is consistent with detection of the precursor n-3 PUFAs EPA and docosahexaenoic acid (DHA) in human epidermal phospho-

A

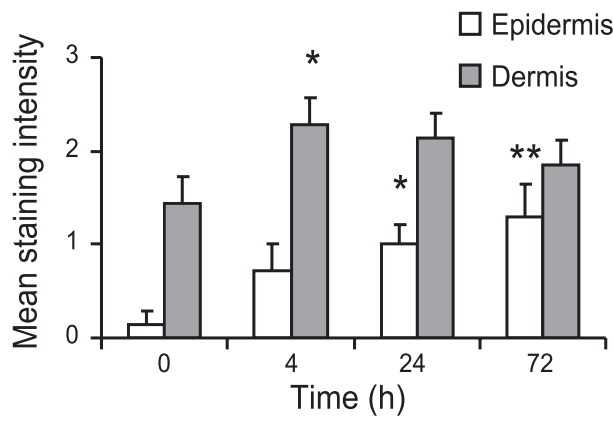

B

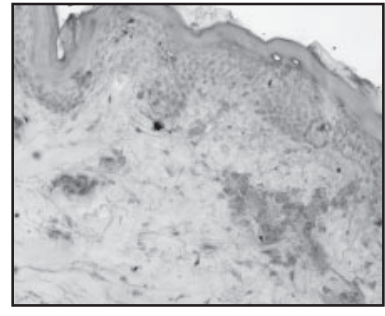

C

D
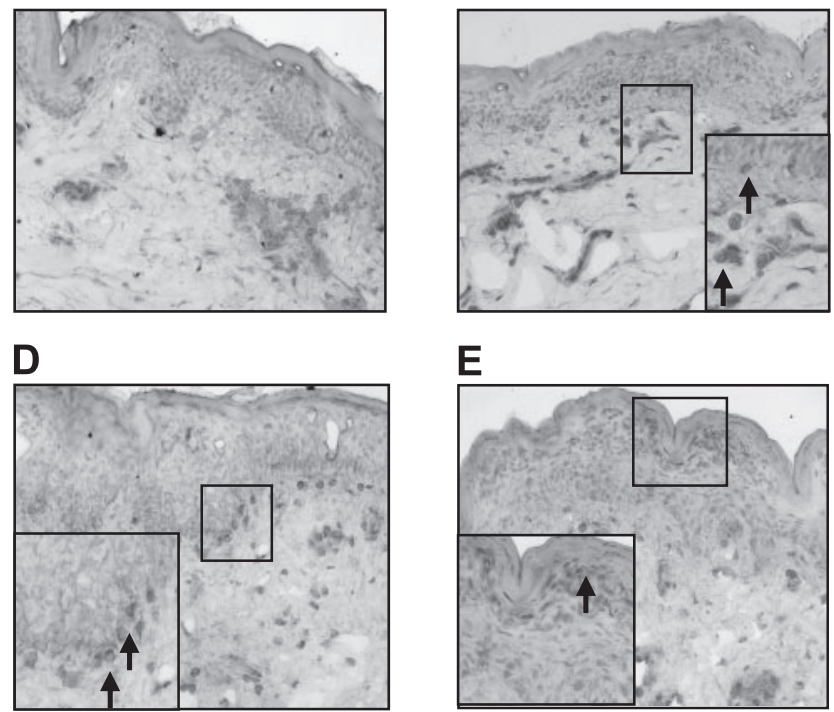

E

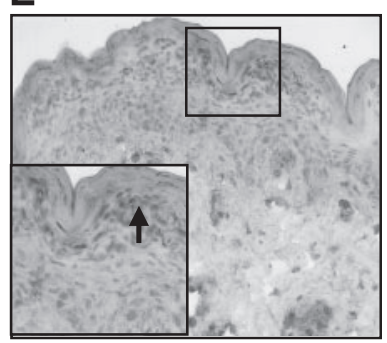

Figure 7. Expression of 12-LOX in the epidermis and dermis during the sunburn response. Graphical presentation of time course of 12-LOX $(A)$, with representative photomicrographs of sections from unirradiated skin $(B)$ and skin at $4 \mathrm{~h}(C)$, $24 \mathrm{~h}(D)$, and $72 \mathrm{~h}(E)$ after UVB exposure. Punch biopsy samples were collected from buttock skin of healthy volunteers prior to and at intervals after exposure to $4 \times$ MED of UVB. Immunohistochemical analysis was performed to determine relative levels of 12-LOX present in dermis and epidermis. Frozen sections were scored for staining intensity $(\times 200$ original view; see Fig. 6). Arrows indicate 12-LOX staining. Results are expressed as mean \pm SE staining intensity; $n=7$. $* P<0.05 ; * * P<0.01$ vs. baseline. 

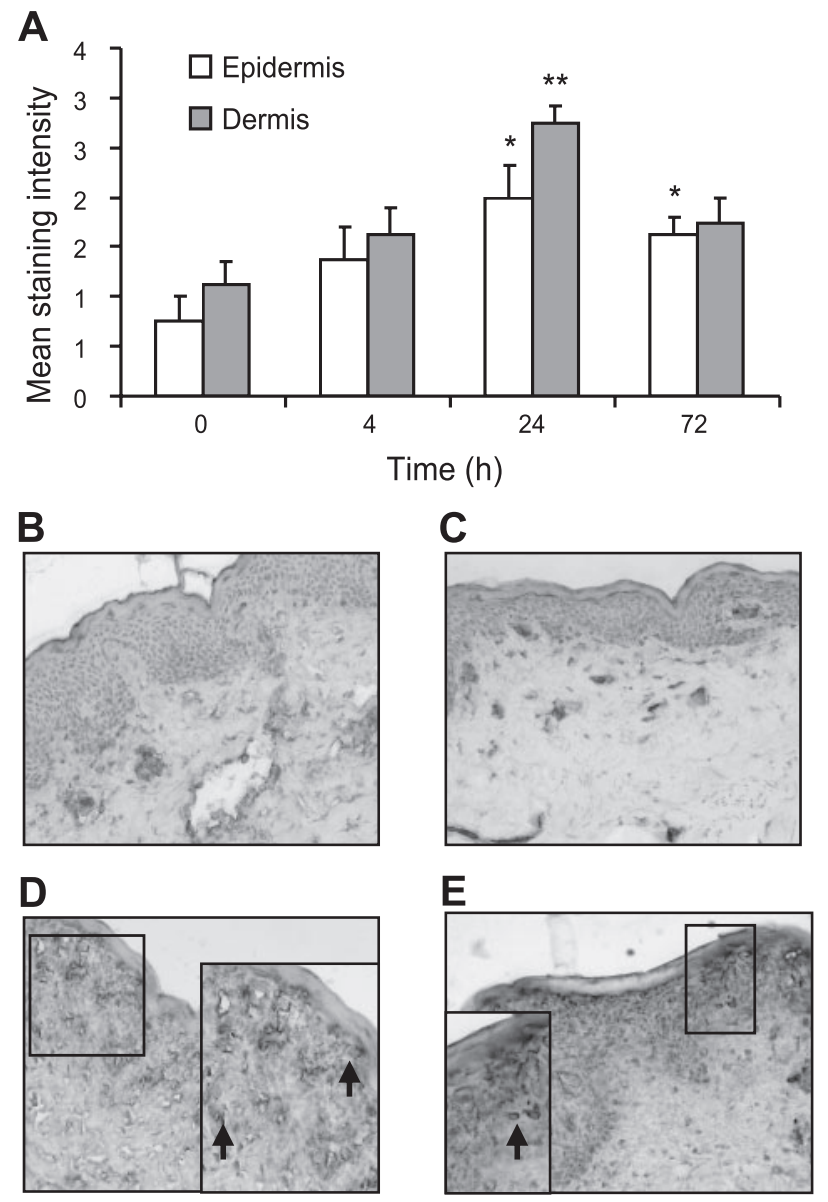

Figure 8. Expression of 15-LOX in the epidermis and dermis following UVB irradiation. Graphical presentation of time course of 15-LOX expression $(A)$, with representative photomicrographs of sections from unirradiated skin $(B)$ and skin at $4 \mathrm{~h}(C), 24 \mathrm{~h}(D)$, and $72 \mathrm{~h}(E)$ after UVB exposure. Punch biopsy samples were collected from buttock skin of healthy volunteers prior to and at intervals after exposure to $4 \times$ MED of UVB. Immunohistochemical analysis was performed on frozen skin sections to determine relative levels of 15-LOX in dermis and epidermis (see Fig. 6). Arrows indicate 15 -LOX staining. Results are expressed as mean \pm SE staining intensity; $n=8$. $* P<0.05, * * P<0.01$ vs. baseline.

lipids $(9,30)$. In many respects, $\mathrm{PGE}_{3}$ is believed to possess similar functions to $\mathrm{PGE}_{2}$, but with reduced potency (31), and thus $\mathrm{PGE}_{3}$ may contribute to the erythema following UVB, although it may also reduce the efficacy of $\mathrm{PGE}_{2}$ through acting as its partial agonist. Although neither $\mathrm{PGE}_{2}$ nor $\mathrm{PGE}_{3}$ was significantly elevated at $72 \mathrm{~h}$, they appear not to have returned to baseline level at this time point, and the combined effects of the vasodilatory prostaglandins, together with nitric oxide $(1,7)$, could continue to influence sunburn erythema at the later time point. Cyclooxygenase and nitric oxide synthase inhibitors each reduce the erythemal component of the sunburn response at least to $48 \mathrm{~h}$ after UVB exposure (1).

During sunburn, neutrophils accumulate in the dermis $(2,3)$ where they exert proinflammatory activities, including further release of mediators with chemoattractant properties. The infiltration occurs from $4 \mathrm{~h}$

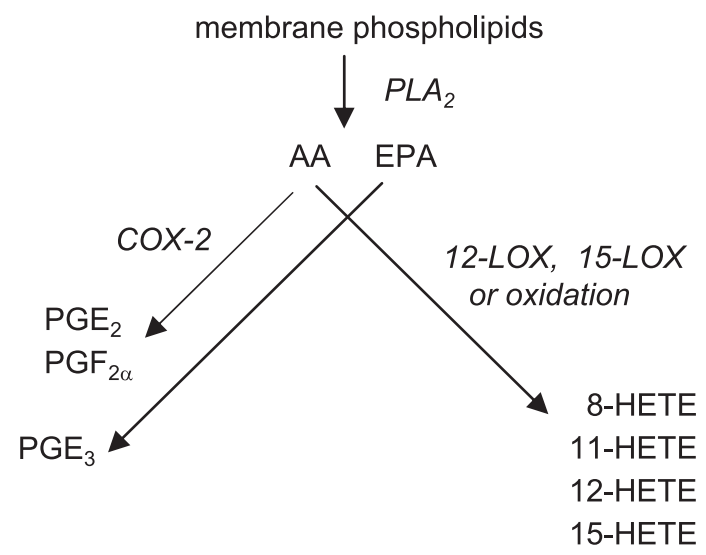

Scheme 1. COX- and LOX-generated PUFA metabolites. Simplified illustration to show COX- and LOX-generated metabolites of the principal long-chain n-6 and n-3 PUFAs, $\mathrm{AA}$, and EPA, respectively, focusing on eicosanoids relevant to the present study.

after UVB onward and is consistent with our observations of the increase in a range of chemoattractant HETE. Neither 11-HETE nor 8-HETE has to our knowledge previously been reported in human skin, while 8-HETE has been detected in mouse skin (32). Their derivation is uncertain but potentially results from a combination of LOX, CYP450, and nonenzymatic oxidation pathways (11). Because both are potent neutrophil chemoattractants in in vitro and experimental models in other systems (18), they are anticipated to make a substantial contribution to the leukocyte chemoattraction in sunburn, particularly as there is significant elevation of 11-HETE as early as $4 \mathrm{~h}$. The potent keratinocyte-derived chemoattractant 12-HETE produces a mixed neutrophilic and mononuclear infiltrate following intradermal injection (33) and has been shown in vitro to be a chemoattractant for lymphocytes in addition to neutrophils (17). While 12-HETE has

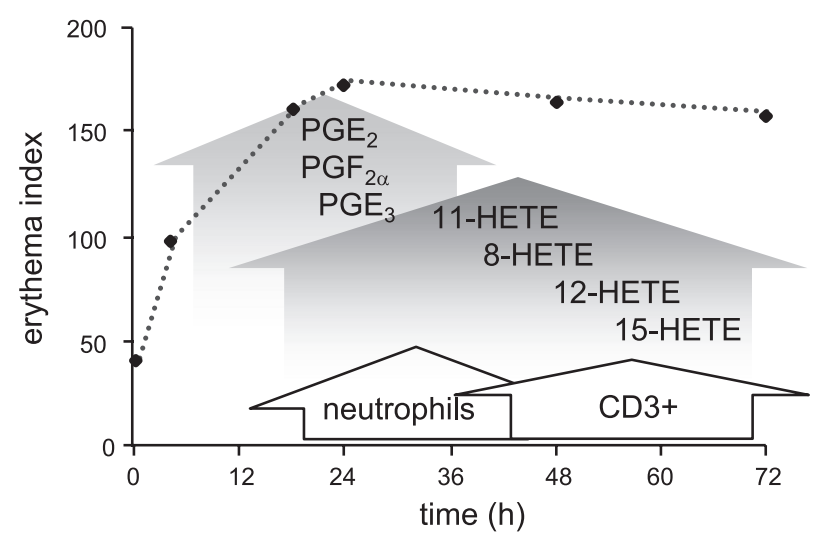

early: inflammation vasodilatation, chemotaxis

late: resolution repair

Scheme 2. Composite illustration of the principal events of the sunburn response. Illustration shows the skin erythemal and leukocytic responses to UVB, indicating proposed key time points for contributions of COX- and LOX-generated eicosanoids. 
been reported to be elevated in cutaneous inflammatory states, i.e., in psoriasis (34) and contact dermatitis (35), Black et al. (35) found 12-HETE elevated at 24 but not $72 \mathrm{~h}$ after UV exposure in a study of skin blister fluid in 6 subjects, and Grundmann et al. (36) detected 12-HETE at 3 but not $24 \mathrm{~h}$ in dermal microdialysate in 3 subjects. Our findings, in a larger subject group, of higher and more sustained 12-HETE up-regulation, contrast with these reports and support a significant role for this 12-LOX-derived metabolite in the sunburn response, potentially including the prolonged (to $72 \mathrm{~h}$ ) $\mathrm{CD}^{+}$cell infiltration.

The neutrophil chemoattractants $\mathrm{LTB}_{4}$, believed to play a role in a range of skin inflammatory conditions (37), and 5-HETE were undetectable. It is conceivable that these mediators were present in a cellular compartment inaccessible for sampling via the suction blister method, since a slight although nonstatistically significant UV-associated rise in 5-HETE was detected in dermal microdialysate (36). However, $\mathrm{LTB}_{4}$ has been detected in suction blister fluid in a range of other skin inflammatory states $(38,39)$, and our data correspond with earlier reports of lack of up-regulation of $\mathrm{LTB}_{4}$ and 5-HETE following UVB exposure of mouse skin $(40,41)$. UVB-up-regulated $\mathrm{PGE}_{2}$ may inhibit 5-LOX and thereby production of the $\mathrm{LT}_{4}$ series (26), while 15-HETE may also inhibit $\mathrm{LTB}_{4}$ synthesis (42). Thus, a specific proinflammatory profile of LOX metabolite expression is apparent in sunburn, distinct from that observed in other skin inflammatory states, providing evidence against the supposition that " $\mathrm{LTB}_{4}$ may be a prerequisite for emigration of leukocyte into dermis" (43).

A further novel, and intriguing, finding was the significant UVB up-regulation of the anti-inflammatory eicosanoid 15-HETE, exhibiting a later response with mean levels observed to double between 48 and $72 \mathrm{~h}$ and potentially rising beyond $72 \mathrm{~h}$. This 15 -LOX metabolite has been shown to inhibit the synthesis of proinflammatory eicosanoids $\mathrm{PGE}_{2}$ and 12-HETE in in vitro models $(14,44)$ and to inhibit the activity of 12-LOX in epidermis (45) and 5-LOX in neutrophils (44). Hence, the later elevation of this mediator could reflect a role in the resolution of sunburn, including limitation of the neutrophil influx. Other eicosanoids could potentially also possess restorative roles at later time points, including, paradoxically, 12-HETE, which is still rising at $72 \mathrm{~h}$, and is described to induce fibroblast chemotaxis (46).

In summary, we have observed overlapping phases in lipid mediator profile during the sunburn response, from mainly COX-derived proinflammatory products in the early stages, to predominantly LOX products during the leukocyte infiltration phases and resolution phase, in association with UVB up-regulation of COX-2 and 12- and 15-LOX expression (Scheme 2). This study supports involvement of a specific pattern of eicosanoid products in this self-limiting inflammatory reaction. While both n-3 and n-6 PUFA-derived prostanoids are elevated and may contribute to the vasodilatation re- sponse, 8-HETE, 11-HETE, and 12-HETE are candidate mediators of UVB-induced leukocyte chemoattraction. Our findings of an elevation of the anti-inflammatory metabolite 15-HETE in the later stages of this response warrants further examination of its potential role in resolving the inflammation. A robust resolution response may be important in protection against pathological states linked with sunburn, namely skin cancer and types of photosensitivity.

The authors acknowledge The Wellcome Trust, project WT077714, for funding this research. The Dermatological Sciences Research Group is supported by the National Institute for Health Research Manchester Biomedical Research Centre. The authors thank Andrew Healey (University of Bradford Analytical Centre) for technical support.

\section{REFERENCES}

1. Rhodes, L. E., Belgi, G., Parslew, R., McLoughlin, L., Clough, G. F., and Friedmann, P. S. (2001) Ultraviolet-B-induced erythema is mediated by nitric oxide and prostaglandin $\mathrm{E}_{2}$ in combination. J. Invest. Dermatol. 117, 880-885

2. Hawk, J. L., Murphy, G. M., and Holden, C. A. (1988) The presence of neutrophils in human cutaneous ultraviolet-B inflammation. Br. J. Dermatol. 118, 27-30

3. Strickland, I., Rhodes, L. E., Flanagan, B. F., and Friedmann, P. S. (1997) TNF- $\alpha$ and IL-8 are upregulated in the epidermis of normal human skin after UVB exposure: correlation with neutrophil accumulation and E-selectin expression. J. Invest. Dermatol. 105, 763-768

4. Teunissen, M. B. M., Piskin, G., di Nuzzo, S., Sylva-Steenland, R. M. R., de Rie, M. A., and Bos, J. D. (2002) Ultraviolet B radiation induces a transient appearance of IL-4+ neutrophils, which support the development of Th2 responses. J. Immunol. 168, 3732-3739

5. Di Nuzzo, S., Sylva-Steenland, R. M. R., de Rie, M. A., Das, P. K., Bos, J. D., and Teunissen, M. B. M. (1998) UVB Radiation preferentially induces recruitment of memory $\mathrm{CD}_{4}+\mathrm{T}$ cells in normal human skin: Long-term effect after a single exposure. $J$. Invest. Dermatol. 110, 978-981

6. Black, A. K., Greaves, M. W., Hensby, C. N., and Plummer, N. A (1978) Increased prostaglandins $\mathrm{E}_{2}$ and $\mathrm{F}_{2 \alpha}$ in human skin at 6 and $24 \mathrm{~h}$ after ultraviolet B irradiation $(290-320 \mathrm{~nm})$. Br. J. Clin. Pharmacol. 5, 431-436

7. Warren, J. B. (1994) Nitric oxide and human skin blood flow responses to acetylcholine and ultraviolet light. FASEB J. 8, 247-251

8. Ziboh, V. A. (1992) Prostaglandins, leukotrienes, and hydroxy fatty acids in epidermis. Semin. Dermatol. 11, 114-120

9. Rhodes, L. E., O'Farrell, S., Jackson, M. J., and Friedmann, P. S. (1994) Dietary fish-oil supplementation in humans reduces UVB-erythemal sensitivity but increases epidermal lipid peroxidation. J. Invest. Dermatol. 103, 151-154

10. Burrall, B. A., Wintroub, B. U., and Goetzl, E. J. (1985) Selective expression of 15-lipoxygenase activity by cultured human keratinocytes. Biochem. Biophys. Res. Commun. 133, 208-213

11. Kühn, H., and O'Donnell, V. B. (2006) Inflammation and immune regulation by 12/15-lipoxygenases. Prog. Lipid. Res. 45, 334-356

12. Capdevila, J. H., Falck, J. R., and Harris, R. C. (2000) Cytochrome P450 and arachidonic acid bioactivation: molecular and functional properties of the arachidonate monooxygenase. $J$. Lipid Res. 41, 163-181

13. Buckman, S. Y., Gresham, A., Hale, P., Hruza, G., Anast, J., Masferrer, J., and Pentland, A. P. (1998) COX-2 expression is induced by UVB exposure in human skin: implications for the development of skin cancer. Carcinogenesis 19, 723-729

14. Yoo, H., Jeon, B., Jeon, M.-S., Lee, H., and Kim, T-Y. (2008) Reciprocal regulation of 12- and 15-lipoxygenases by UV-irradiation in human keratinocytes. FEBS Lett. 582, 3249-3253 
15. Masoodi, M., and Nicolaou, A. (2006) Lipidomic analysis of twenty-seven prostanoids and isoprostanes by liquid chromatography/electrospray tandem mass spectrometry. Rapid Commun. Mass Spectrom. 20, 3023-3029

16. Masoodi, M., Mir, A. A., Petasis, N. A., Serhan, C. N., and Nicolaou, A. (2008) Simultaneous lipidomic analysis of three families of bioactive lipid mediators leukotrienes, resolvins, protectins and related hydroxy-fatty acids by liquid chromatography/electrospray ionisation tandem mass spectrometry. Rapid Commun. Mass Spectrom. 22, 75-83

17. Bacon, K. B., Camp, R. D., Cunningham, F. M., and Woollard, P. M. (1988) Contrasting in vitro lymphocyte chemotactic activity of the hydroxyl enantiomers of 12-hydroxy-5,8,10,14eicosatetraenoic acid. Br. J. Pharmacol. 95, 966-974

18. Goetzl, E. J., Brash, A. R., Tauber, A. I., Oates, J. A., and Hubbard, W. C. (1980) Modulation of human neutrophil function by monohydroxy-eicosatetraenoic acids. Immunology 39, 491-501

19. Rhodes, L. E., Durham, B. H., Fraser, W. D., and Friedmann, P. S. (1995) Dietary fish oil reduces basal and ultraviolet B-generated $\mathrm{PGE}_{2}$ levels in skin and increases the threshold to provocation of polymorphic light eruption. J. Invest. Dermatol. 105, 532-535

20. Black, A. K., Fincham, N., Greaves, M. W., and Hensby, C. N. (1980) Time course changes in levels of arachidonic acid and prostaglandins $\mathrm{D}_{2}, \mathrm{E}_{2}, \mathrm{~F}_{2 \alpha}$ in human skin following ultraviolet $\mathrm{B}$ irradiation. Br. J. Clin. Pharmacol. 10, 453-457

21. Crunkhorn, P., and Willis, A. L. (1971) Cutaneous reactions to intradermal prostaglandins. Br. J. Pharmacol. 41, 49-56

22. Juhlin, L., and Michaëlsson, G. (1969) Cutaneous vascular reactions to prostaglandins in healthy subjects and in patients with urticaria and atopic dermatitis. Acta Derm. Venereol. 49, 251-261

23. Hedqvist, P. (1977) Basic mechanisms of prostaglandin action on autonomic neurotransmission. Annu. Rev. Pharmacol. Toxicol. 17,259

24. Raud, J., Dahlen, S. E., Sydbom, A., Lindbom, L., and Hedqvist, P. (1988) Enhancement of acute allergic inflammation by indomethacin is reversed by prostaglandin $\mathrm{E}_{2}$ : apparent correlation with in vivo modulation of mediator release. Proc. Natl. Acad. Sci. U. S. A. 85, 2315-2319

25. Bagga, D., Wang, L., Farias-Eisner, R., Glaspy, J. A., and Reddy, S. T. (2003) Differential effects of prostaglandin derived from $\omega-6$ and $\omega-3$ polyunsaturated fatty acids on COX-2 expression and IL-6 secretion. Proc. Natl. Acad. Sci. U. S. A. 100, 1751-1756

26. Levy, B. D., Clish, C. B., Schmidt, B., Gronert, K., and Serhan, C. N. (2001) Lipid mediator class switching during acute inflammation: signals in resolution. Nat. Immunol. 2, 612-619

27. Gewirtz, A. T., Collier-Hyams, L. S., Young, A. N., Kucharzik, T., Guilford, W. J., Parkinson, J. F., Williams, I. R., Neish, A. S., and Madara, J. L. (2002) Lipoxin $\mathrm{A}_{4}$ analogs attenuate induction of intestinal epithelial proinflammatory gene expression and reduce the severity of dextran sodium sulfate-induced colitis. J. Immunol. 168, 5260-5267

28. Serhan, C. N., Jain, A., Marleau, S., Clish, C., Kantarci, A., Behbehani, B., Colgan, S. P., Stahl, G. L., Merched, A., Petasis, N. A., Chan, L., and Van Dyke, T. E. (2003) Reduced inflammation and tissue damage in transgenic rabbits overexpressing 15-lipoxygenase and endogenous anti-inflammatory lipid mediators. J. Immunol. 171, 6856-6865

29. Vachier, I., Chanez, P., Bonnans, C., Godard, P., Bousquet, J., and Chavis, C. (2002) Endogenous anti-inflammatory mediators from arachidonate in human neutrophils. Biochem. Biophys. Res. Commun. 290, 219-224

30. Rhodes, L. E., Shahbakhti, H., Azurdia, R. M., Moison, R. M. W., Steenwinkel, M.-J. S. T., Homburg, M. I., Dean, M. P., McArdle, F., Beijersbergen van Henegouwen, G. M. J., Epe, B., and Vink, A. A. (2003) Effect of eicosapentaenoic acid, an omega-3 polyunsaturated fatty acid, on UVR-related cancer risk in hu- mans. An assessment of early genotoxic markers. Carcinogenesis 24, 919-925

31. Lands, W. E. (1992) Biochemistry and physiology of n-3 fatty acids. FASEB J. 6, 2530-2536

32. Gschwendt, M., Furstenberger, G., Kittstein, W., Besemfelder, E., Hull, W. E., Hagedorn, H., Opferkuch, H. J., and Marks, F. (1986) Generation of the arachidonic acid metabolite 8-HETE by extracts of mouse skin treated with phorbol ester in vivo; identification by 1H-n.m.r., and GC-MS spectroscopy. Carcinogenesis 7, 449-455

33. Dowd, P. M., Black, A. K., Woollard, P. M., Camp, R. D. R., and Greaves, M. W. (1985) Cutaneous responses to 12-hydroxy5,8,10,14-eicosatetraenoic acid (12-HETE). J. Invest. Dermatol. $84,537-541$

34. Hammarström, S., Lindgren, J. A., Marcelo, C., Duell, E. A., Anderson, T. F., and Voorhees, J. J. (1979) Arachidonic acid transformations in normal and psoriatic skin. J. Invest. Dermatol. 73, $180-183$

35. Black, A. K., Barr, R. M., Wong, E., Brain, S., Greaves, M. W., Dickinson, R., Shroot, B., and Hensby, C. N. (1985) Lipoxygenase products of arachidonic acid in human inflamed skin. Br. J. Clin. Pharmacol. 20, 185-190

36. Grundmann, J. U., Wiswedel, I., Hirsch, D., and Gollnick, H. P. (2004) Detection of monohydroxyeicosatetraenoic acids and $\mathrm{F}_{2}$-isoprostanes in microdialysis samples of human UV-irradiated skin by gas chromatography-mass spectrometry. Skin Pharmacol. Physiol. 17, 37-41

37. Camp, R. D., Coutts, A. A., Greaves, M. W., Kay, A. B., and Walport, M. J. (1983) Responses of human skin to intradermal injection of leukotrienes $\mathrm{C}_{4}, \mathrm{D}_{4}$, and $\mathrm{B}_{4}$. Br. J. Pharmacol. 80, 497-502

38. Barr, R. M., Brain, S., Camp, R. D., Cilliers, J., Greaves, M. W. Mallet, A. I., and Misch, K. (1984) Levels of arachidonic acid and its metabolites in the skin in human allergic and irritant contact dermatitis. Br. J. Dermatol. 111, 23-28

39. Ruzicka, T., Simmet, T., Peskar, B. A., and Ring, J. (1986) Skin levels of arachidonic acid-derived inflammatory mediators and histamine in atopic dermatitis and psoriasis. J. Invest. Dermatol. 86, 105-108

40. Ruzicka, T., Walter, J. F., and Printz, M. P. (1983) Changes in arachidonic acid metabolism in UV-irradiated hairless mouse skin. J. Invest. Dermatol. 83, 300-303

41. Ruzicka, T., and Przybilla, B. (1986) Eicosanoids in skin UV inflammation-lack of leukotriene $\mathrm{B}_{4}$ elevation in UVB-induced dermatitis. Photodermatology 3, 306-307

42. Profita, M., Sala, A., Siena, L., Henson, P. M., Murphy, R. C., Paterno, A., Bonanno, A., Riccobono, L., Mirabella, A., Bonsignore, G., and Vignola, A. M. (2002) Leukotriene $\mathrm{B}_{4}$ production in human mononuclear phagocytes is modulated by interleukin-4-induced 15-lipoxygenase. J. Pharmacol. Exp. Ther. 300, $868-875$

43. Dahlén, S. E., Björk, J., Hedqvist, P., Arfors, K. E., Hammarström, S., Lindgren, J. A., and Samuelsson, B. (1981) Leukotrienes promote plasma leakage and leukocyte adhesion in postcapillary venules: in vivo effects with relevance to the acute inflammatory response. Proc. Natl. Acad. Sci. U. S. A. 78, 3887-3891

44. Vanderhoek, J. Y., Bryant, R. W., and Bailey, J. M. (1980) Inhibition of leukotriene biosynthesis by the leukocyte product 15- hydroxy-5,8,11,13-eicosatetraenoic acid. J. Biol. Chem. 255, $10064-10066$

45. Kragballe, K., and Voorhees, J. J. (1987) Eicosanoids in psoriasis-15-HETE on the stage. Dermatologica 174, 209-213

46. Rieger, G., Hein, R., Ruzicka, T., Wach, F., Adelemann-Grill, B., and Krieg, T. (1987) Biologic activities of eicosanoids on fibroblasts in culture. J. Invest. Dermatol. 89, 339

Received for publication May 12, 2009 Accepted for publication June 18, 2009. 